\title{
The future of copyright in the age of convergence: Is a new approach needed for the new media world?
}

Neal Geach LLM

Lecturer,

University of Hertfordshire,

7 Hatfield Road,

St Albans,

Hertfordshire,

AL1 3RR

N.Geach@herts.ac.uk

\section{$\underline{\text { Abstract }}$}

In 2007 the European Commission finalised its proposals for replacing the Television without Frontiers

Directive. The resultant Audiovisual Media Services Directive aims to provide a more suitable regulatory framework for the creative industries allowing it to benefit from the opportunities brought about by convergence. Convergence is the coming together of different technologies which have distinct functions to create one medium which performs each divergent function. The prime illustration of convergent technologies is arguably the coming together of telecommunications and broadcasting, through the internet and digital technology, so as to enable us to make voice telephony calls and watch television while sat at a computer. However, while convergence has created opportunities for the industry it has also created threats in that the same technology, namely the internet, is also being used to infringe the copyright of content producers on a far greater scale. Wide scale infringement will have a negative impact on the creation of new works; without protection from illegal copying the work will have less economic value. The substantive provisions of the Directive focus on regulatory issues such as advertising restrictions and encouraging media pluralism and have received criticism from within the industry. However, it is argued that regardless of any other potential flaws the new Directive may have (which are beyond the scope of the present discussion); the biggest weakness is not addressing the link between converged media platforms and the potential for 
increased copyright infringement. This omission on the part of the Directive may be explained by the presence of the Copyright Directive, but this is dependent on the Copyright Directive being adequate for the new media age. This work evaluates whether the traditional approach to copyright protection is still the most suitable and whether in fact the arguments advanced in favour of this approach still have merit in the converged age. To this end an evaluation of a creative commons approach is provided in order to see whether this may have more advantages.

Key words: convergence, audiovisual media, copyright, commons 


\section{The future of copyright in the age of convergence: Is a new approach needed for the new}

media world? ${ }^{1}$

\section{The need for Audiovisual Content Copyright Protection}

Phonographic Performance Ltd UK has described the creative industries as "the key to prosperity in modern economies." ${ }^{2}$ As a body that works on behalf of performers and record companies, this statement could be dismissed as mere industry self-hype. However, official statistics would indicate them to be correct. In 2004 the industry contributed over $£ 56$ billion to the UK economy; growing at an average rate of 5\% per year between 1997 and 2004. ${ }^{3}$ To put this into some context; the average growth for the UK economy as a whole was only $3 \%{ }^{4}$ As a sector the exact employment figure "is not entirely clear" but is between 1.15 and 2 million. ${ }^{5}$ These figures will surely increase as greater access to higher quality content is allowed due to the continued expansion of converged technologies, such as the mounting ability to watch television on mobile phones, and also as technology develops to allow better quality images to be created and shown. Therefore, the government argues "it is vital that creative businesses are fully able to exploit the exciting new media technology that has opened up access to creative content. However, for businesses to be able to make returns on their creativity and invest in new talent and innovation, it is also important that they have the necessary protection." ${ }^{, 6}$ In other words, the creative content industry which provides work for the new audiovisual media services is held up as a prime example of the traditional economic justifications for imposing strict copyright protection. The argument is that investment in design and development will not be forthcoming without the incentive that protection provides. As Bainbridge suggests, "[w]hy spend large sums of money to develop [content] that could be copied freely without recompense?"” 


\section{Threats and Opportunities for Audiovisual Media in the Converged Environment}

The new environment in which audiovisual media service providers find themselves operating offers potentially huge benefits but also creates threats to their business viability. Converged technologies, such as internet protocol television (herein IPTV), offer the chance to distribute content at lower costs, to wider audiences and so they are appealing business models. However, converged media platforms, be it IPTV or mobile phone television, need high quality content to drive uptake. The increased competition for audience share between traditional broadcasters has also driven demand for higher quality content. This has led Patrick Bradley of Ingenious Media to declare that "content is king" in today's audiovisual environment. ${ }^{8}$ Thus, the opportunity exists for content creators to gain increased exposure through a variety of outlets that now exist for their work. ${ }^{9}$ This could, if the quality is sufficient, lead to increased revenue to pay for further innovation. Additionally, the Internet allows them to miss out 'the middle man' and sell their content directly to viewers and further increase revenues; even content providers such as $\mathrm{Sky}^{10}$ can benefit from the increased content production that arises from this demand. ${ }^{11}$ Content can also be used to attract business for any complementary on-demand services being offered by the broadcaster.

However, despite these opportunities for increased exposure and driving revenue, the same technology that allows viewers greater access to content is also a threat. Digital technology allows for a better quality copy of content to be produced and ensures that the quality does not diminish through repeated use. Internet peer-to-peer networks and technologies, such as BitTorrent, allow for the fast and efficient up/downloading of large files such as films and TV programmes. This, in turn, provides for easier distribution amongst individuals. As the content being distributed is of good quality, durable, quick to download in order to view, and either free or low cost, more people are utilising the opportunity that the technology brings and not purchasing the content through traditional outlets. This activity is a major threat to the industry as it reduces the commercial exploitation potential of content creators and providers. To take Sky, if ' 24 ' is freely 
available in good quality on the internet, for no cost, then there is no incentive to pay a monthly subscription to the company. This threat has led to the observation that "IPTV platforms will only succeed if companies can differentiate from the three other delivery platforms - terrestrial, cable and satellite. They need [intellectual property] rights. If those rights are secured, current TV broadcast models - and the EC's proposals - will become irrelevant." ${ }^{12}$

Notwithstanding the illegal copying and distribution of audiovisual content, on-demand services are themselves a problem. The purpose of on-demand is to allow viewers to legally download a particular piece of content using the Internet. However, the Internet is obviously global and any website in the world is accessible to any person wherever they may be. Initially this may not appear to be a problem; surely this is a benefit that the Internet can provide a wider audience for content? This may be so, but the flipside is that a person, in for example Germany, should be able to go on the website of a UK content producer and download that content after it has been transmitted in the UK. The issue is that this could be before that piece of content will have been shown in Germany, most likely under an exclusive distribution agreement between the original company and the German company providing the retransmission. Such exclusive right agreements can be extremely lucrative for the purchaser, by either helping to drive subscriptions or through generating higher value sponsorships or traditional advertisement spots. This is obviously in addition to the party selling the rights who can generate significant revenues. ${ }^{13}$ On-demand, with the global nature of the Internet, potentially makes such agreements worthless. This dilemma is resolved by preventing access to on-demand services from foreign IP addresses, which is the situation with both the BBC's and ITV's on-demand services. This is arguably a precursor to the Balkanisation of the Internet which is widely agreed to be a detrimental development. 


\section{Copyright Protection within the Audio Visual Media Services Directive}

As the audiovisual content industry is an important sector of the economy, ${ }^{14}$ copyright protection is needed if it is to continue its current growth. It is suggested that a regulatory framework, which seeks to regulate audiovisual media in order for it to flourish, should have copyright close to its foundations. There would appear to be little logic in not including copyright provisions within the overall regulatory framework, if only for "Better Regulation" purposes. ${ }^{15}$

However, the new the AVMS Directive, which provides the new regulatory framework for IPTV and traditional broadcasting, does not take this joined up approach. The purpose of the Directive is to overhaul the regulatory framework for the European broadcasting industry. This has been necessary primarily due to convergence bringing about the possibility to watch TV on-line. The principal objective of the Directive is to create a modern but technologically-neutral framework which allows for traditional television functions to be taken over gradually by audiovisual media services. The Directive can also be seen as part of the EU's wider i2010 initiative, seeking to increase growth and jobs in the information society and media industries by creating a regulatory environment that encourages investment and innovation. Under the new framework, the essential nature of an "audiovisual media service" is that it is a service under the editorial responsibility of a media service provider which has the principal purpose of providing programmes in order to inform, entertain or educate the general public. Such services will either be a "television broadcast" or an "on-demand service". This distinction determines which regulatory provisions apply to the service in question. For present purposes it is important to note the definitions of "television broadcast" and "on-demand service" as provided by article 1 . The former is stated as being "an audiovisual media service provided by a provider for simultaneous viewing of programmes on the basis of a programme schedule". The latter is defined "as an audiovisual media service provided by a media service provider for the viewing of programmes at the moment 
chosen by the user at his/her individual request on the basis of a catalogue of programmes selected by the media service provider".

Within the Directive, article 3c is the only provision that makes reference to the issue of copyright; even then this is in the limited scope of prohibiting service providers from transmitting cinematographic works outside the periods agreed with the rights holders. Ironically, this is highlighted in a Parliamentary report $^{16}$ (herein The Report) as something that encourages copyright infringement. In recommendation 15 it "accept[s] the argument, in principle, that delaying universal access to film through the use of release windows, and holding back rights to broadcast television programming via new media, contributes to a climate in which piracy flourishes."17

There is a further indirect reference to copyright in the AVMS Directive through the provisions of chapter IIc which covers exclusive rights and short news provisions. These provide that in the interests of media pluralism where an event has been acquired exclusively by one "broadcaster", that broadcaster can be made to provide "fair, reasonable and non-discriminatory" access to other broadcasters for the purpose of short news reports. ${ }^{18}$ Compensation arrangements should be available under the Member States' legal systems for a breach of the access terms. ${ }^{19}$

No other references to copyright are made in the framework, ${ }^{20}$ yet the long standing argument in favour of copyright protection is that without it, the same economic goals which the AVMS Directive seeks to achieve cannot be met. There is arguably a contradiction here, particularly as no significant mention of copyright is made in the AVMS Directive; yet the technology that has allowed the present situation to evolve is being cited as a threat to the industry's very existence. The EU may point to existing legislation that provides copyright protection as the reason for its omission here. However, this assumes that existing copyright protection is suited to the new, dynamic audiovisual environment that the new framework was a response to. 


\section{Existing EU Copyright Protection}

The EU's Copyright Directive ${ }^{21}$ states that through a harmonised legal framework on copyright, not only will there be a higher level of protection, but also a fostering of "substantial investment in creativity and innovation ... and lead to growth and increased competitiveness of European industry, both in the area of content provision.....22 This suggests a close operation between this and the broadcasting framework; particularly as it goes on to state that intellectual property rights are "necessary" to ensure the availability of an attractive return on the "considerable" investment needed to produce on-demand services. ${ }^{23}$

The Copyright Directive provides, for present purposes, two key rights for content creators. The first is in article 2, the reproduction right. This gives Member States the ability to provide for certain creators the exclusive right to decide whether or not they allow any form of reproduction of their work. For present purposes, the important group of creators that this right applies to is "broadcasting organisations"; it is also clear from the wording of the section that broadcasts transmitted over the internet were intended to be protected. $^{24}$

The second right allows for the provision of an exclusive right to determine whether a work is communicated to, and made available to, the public. This right includes whether to make the work available to the public in such a way that the work may be accessed "from a place and at a time individually chosen" by a member of the public, i.e. on-demand. ${ }^{25}$ The provision of an exclusive right to determine communication to the public applies to authors only. ${ }^{26}$ The right for making a work available to the public applies to the same groups as the reproduction right and so includes "broadcasting organisations".

The result appears that copyright holders of audiovisual media content will have an exclusive right to determine whether their work is reproduced, communicated or made available to the public, ${ }^{27}$ and therefore, fills the gap within the AVMS Directive. An individual is prohibited from copying content and then uploading it to a website for others to download, as this would involve the reproducing and making available 
of that content. It is suggested that this view is mistaken as it is only applicable to a confined range of audiovisual media situations. The Copyright Directive contains no definitions as to what constitutes the groups of recognised right holders, most notably, "broadcasting organisation". At the time of the implementation of the Copyright Directive, the meaning of the term broadcasting may have been obvious, or it may have been logical to apply the definition within the old Television without Frontiers Directive which was in force at the time. However, the concept of broadcasting is redefined by the AVMS Directive; in fact, the term "broadcasting organisation" is completed omitted from the AVMS Directive. ${ }^{28}$ Can it really be said that a Directive passed in 2001 can have the meaning of another Directive passed some six years later without the latter expressly stating that its terms are applicable? It is suggested it cannot, otherwise there would never be any reason to pass amending legislation to modernise terms and provisions. The issue that exists therefore is that, if content is watched and copied from a traditional, linear transmission there is protection. The television broadcaster who transmitted the content would clearly be a recognised right holder. Neither is there a problem where the content is transmitted by an on-demand service, as long as the person behind the transmission is a "broadcaster", they should still fit within a "broadcasting organisation". The problem arises where the transmission is performed by a person who solely operates as an on-demand service provider. The distinction made by the new framework between "on-demand service" and "television broadcasting" 29 means an on-demand audiovisual media service provider cannot seriously be classed as a "broadcasting organisation". Therefore, an equivalent to YouTube who transmits content after having the rights assigned to it may have no copyright protection. If the content is produced in-house, so that they are the "author", they would have protection as the copying is a reproduction ${ }^{30}$ and the uploading of the content onto a website would constitute communication to the public. However, any independently sourced work, the amount of which the AVMS Directive seeks to increase, again would fall outside the Copyright Directive. The result, potentially, will be that these independent works are not commissioned, as the economic incentive to do so is 
removed if they can be copied at will by the public. This, in turn, hits media pluralism, another aim of the AVMS Directive.

This void in protection could, perhaps, be filled by technological means. Digital Rights Management (DRM) technologies have been developed in recent years. DRM technologies are used by copyright holders to act as access controls to content and limit the usage of digital media. They have proved controversial as they can restrict content use in ways not prohibited by existing copyright laws, primarily fair use exemptions. $^{31}$ They have also proved controversial due to software and platform interoperability issues; for example, the BBC's new on-demand demand service iplayer has generated complaints. ${ }^{32}$ Due to the DRM used, downloaded transmissions can only be kept for 30 days ( 7 days once watched). This may not be such an issue for a free service such as iplayer, but it is hard to see the sustainability in a commercial model based along these lines. People who pay for downloads are surely entitled to repeat usage, as with music mp3s, yet this is the approach largely taken by Channel 4. The other complaint regarding the iplayer is that due to the DRM being jointly developed by Microsoft, the service is currently only operable on Windows XP. Clearly, as a public service broadcaster this has to change and a more interoperable system is due for role out in the coming months. However, this does then impact on the non-interoperability of other services. There is little incentive to develop an innovative new service, such as a broadcast equivalent of iTunes, if, due to DRM technology within that content or content delivery platform, content cannot be viewed on certain devices needed to view the content. ${ }^{33}$ It is somewhat surprising that at a time when the music industry is moving away from DRM,$^{34}$ broadcasters are implementing them for their on-demand services.

DRM growth and attractiveness for rights holders has flowed from the legal backing the Copyright Directive gives them. ${ }^{35}$ Article 6 states that Member States shall provide "adequate legal protection against the circumvention" of DRM technologies. Additional legal protection is to be offered against the “manufacture, import, distribution, sale, rental...or possession for commercial purposes of devices, products 
or components" which can be used to circumvent DRM technologies. Even the promotion, advertisement or marketing of such devices is prohibited. Further protection is given by article 7 which provides Member States to legally protect against the removal or alteration of the content's electronic rights management information, the information regarding who the rights holder is, and the terms of usage.

Therefore, as things stand, an individual legitimately paying to download a transmission of a programme, and then stripping away the DRM technology in order to watch the programme again, or over a longer period, or to use a different viewing platform, is committing a crime. In the UK, this could potentially lead to 2 years imprisonment and/or a fine ${ }^{36}$ for doing something which at its core level is a legitimate act. ${ }^{37}$ Obviously, this is to act as a deterrent so that the stripped down content is then not made available to the public or distributed. However, the unequal bargaining position of viewers when accepting ${ }^{38}$ that such an act will be copyright infringement, and thus criminal, lends weight to that the view this should not be criminal behaviour and should be allowed as a private use exemption. ${ }^{39}$

Ultimately, the fact that legislative regulation is in place is one thing, but it is common knowledge that copyright infringement through file sharing, or indeed, that solely for private individual consumption is widespread. This raises question marks over the initial justifications of copyright; content production is still occurring after all. In fact, if one includes non-commercial user generated content, on websites such as YouTube, it could be said to be thriving. Generally, the call is always for more robust protection and harsher penalties for infringement; as prosecutions arise the system can be said to be effective. The question must be asked however, as to whether this really is the most appropriate approach. Is there not a better way of giving protection without continually strengthening protection and increasing the deterrents? While certainly beneficial to the copyright holders, it could be argued that such a move is not beneficial to society as a whole as it does not allow as much creativity as there could be. Alternatively, we might instead adopt an approach that may allow for the easier distribution of audiovisual content, which could lead to enhanced cultural 
development and knowledge, as well as providing inspiration for further innovation; such a scenario is after all, another aim of the AVMS Directive.

\section{Creative Commons: A More Realistic Alternative?}

An approach such as that described above, has in fact been advocated by those behind the creative commons movement. They believe that the current copyright protection regime actually hinders creativity - the opposite outcome for its justification. Film Director Davis Guggenheim has explained that before he can shoot any scene for a film he must get "clear rights", not just for the initial story or soundtrack, but also for incidental works such as billboards in the background or drinks that a character may be holding. ${ }^{40}$ The creative idea must go through a process of scrutiny by lawyers to determine what rights may be infringed and then to gain permission for its incidental inclusion. He goes on to cite various examples of litigation that have arisen from this situation. ${ }^{41}$ The result is a constraint on creative and editorial prerogative, as the makeup of a scene is determined by copyright holders. Arguably, this is no different from the influence the AVMS Directive (and its predecessor the Television without Frontiers Directive) has sought to restrict through its advertising restrictions.

There are theoretical arguments to be made against the idea of a creative commons. Chander and Sunder ${ }^{42}$ suggest that people celebrate the advent of the creative commons because of the belief that, as the resource is open to everyone, everyone will exploit it. However, they argue that this is "naïve, idealistic and removed from reality."43 They highlight that, even if a regulated market exists, there will not be equal distribution of the resource. This would suggest that the possibility of greater access will not necessarily result in greater access for the masses. There is certainly merit in this view on a general level, and it would also seem to tie into the theory of the "Tragedy of the Commons", ${ }^{44}$ whereby resources, due to their public availability, are used to extinction or are left in ruin. However, these arguments do not appear to relate to the 
specific issue of broadcasting content where content is non-rivalrous. This is perhaps where the debate over the widespread introduction of a creative commons becomes complex. It may well be that such an approach is not suitable for certain industries; for other industries, the concept may need adaptation. Perhaps the debate over the adoption of a creative commons needs to become more sector-specific; here, the focus is on the broadcasting industry. Some film studios and television broadcasters vigorously resist the arguments in favour of such an approach. The Creators' Rights Alliance has dismissed the idea as something that "would not work in certain types of industries" and just the product of academics "who do not understand the rest of the world. ${ }^{, 45}$

The debate is generally framed by opponents as one of maintaining protection or having none at all. However, the commons approach is about balancing the copyright system to maintain protection on the one hand, but also allowing the greater distribution of ideas. The aim is to get the balance right between the degree of control that content is subject to ${ }^{46}$ and the extent to which it is free. ${ }^{47}$ The proponents of a creative commons argue that such an approach can lead to greater creativity and innovation; particularly when compared to a system which attempts perfect control through divided up proprietary rights such as what we have now. The various layers that make up traditional television ${ }^{48}$ (particularly cable and satellite) have been cited by Lessig as a system that is completely controlled, none are "free". ${ }^{49}$ This can be contrasted with the Internet and its original end-to-end architecture ${ }^{50}$ which means the main layers are free. ${ }^{51}$ This can be illustrated by the vast user generated content that appears on sites such as YouTube: no station controller exists $^{52}$ to decide what can be transmitted, consequently creativity flourishes and creators know there is a guaranteed outlet for their work. Admittedly two points arise from this situation. Firstly, someone making comedy clips in their bedroom could be said to not be on the same commercial level as a multi-million pound broadcasting corporation. Such a person is not necessarily creating work for financial gain, merely for 
creative expression and as such is not affected by copyright infringements of their work. Secondly, it could be said that this lack of a body exercising editorial control encourages copyright infringement. ${ }^{53}$

The result for traditional television broadcasts is, that the most important layer, content, is being restricted through the legislative provisions and technologies described above. This leaves us with a situation that is "perfect control [but one] that threatens to undermine the potential for innovation that the Internet promises... [The] aim should be a system of sufficient control to give artists enough incentive to produce, while leaving free as much as we can for others to build upon and create."54 The rationale for this view is because "[n] othing today, likely nothing since we tamed fire, is genuinely new: Culture, like science and technology, grows by accretion, each new creator building on the works of those who came before. Overprotection stifles the very creative forces it's supposed to nurture."55 While copyright may increase the incentives to produce for creators, it also increases the costs of production, and thus, coupled with the threat of litigation, can act as a barrier to the creative process. Therefore, it could in fact be said to go against its stated justifications.

The commons approach operates by way of a licence system, based on copyright, which the creator of the work uses to attach to the work. In total there are six licences, but these are non-exclusive so that a creator can subsequently sell their work under a licence allowing for the recipient to make commercial use of that work. All of the commons licences allow file sharing provided it is not for monetary gain; if this is the purpose behind the sharing, the licence must not have a non-commercial use restriction attached.

Additionally, the creator can decide whether they want derivative works to be produced from their original, although as noted the system is flexible enough to allow for a change of mind in subsequent cases. If the work is passed on, the new recipient is bound by the same licence terms as the original recipient. If the content in the above loophole scenario has a commons licence attached to it, then that work will be protected under copyright but the action would be legal and thus there is protection balanced with a greater level of 
access. Therefore, it is suggested that this system allows for increased access to material and thus allows creativity to flourish. In turn, commercial use can be made of such work, and so financial incentives also exist as the potential commercial use of the work can be reflected in the amount claimed by the creator for distributing the work to the person who seeks to have possession of it. ${ }^{56}$

There are criticisms that can be levied at this argument. A case can be made for arguing that people can simply circumvent payment for content use in much the same way as they do now with the copying of CDs. However, this can be countered in that it shows it would be no different from the present system. A commons approach will simply decriminalise an act that is in fact an everyday occurrence and in fact gained support in The Report. Again, content is continuing to be produced, regardless of such current illegal activity, by removing the existing usage restrictions production could increase further as the fear of litigation is alleviated from other potential creative talents. ${ }^{57}$ This is not to say that wanton copying that is then distributed as an original piece of content should not remain prohibited. Under a commons approach, the creator of the work has greater power to choose what a recipient can do; if they do not want a derivative work produced they can stipulate that.

There may well be practical problems that would need to be overcome in relation to broadcasting. As the above discussion of the issues faced by David Guggenheim illustrates, a television programme or film may have a whole myriad of component rights, even in just one scene. The issue is whether these rights, if not already available under a creative commons licence, can be obtained if the end product, the show or film, is then able to be distributed freely. The price for granting the use of a piece of music as the soundtrack may be based on the predicted exposure of the produced content. If much wider distribution was to occur than expected, due to the end product be subject to a commons licence, the initial grant of the right to use the music may be undervalued. This could potentially lead to a stifling of innovation as disputes take place over the use of such third party content or the use is simply refused. Ultimately, therefore, the success of adopting a wide- 
scale commons approach is dependent on whether the potential for commercial incentives is convincing enough for the industry and the government who would not want to negatively hit the wider economy. The British Phonographic Industry has not dismissed this idea, but believes that this issue will be determined by the market. ${ }^{58}$ The problem, in the view of British Music Rights, lies with those in the middle of the spectrum that seek to make a career out of their work but are not established enough to lose income from sales. This is the fundamental point, despite the theoretical and practical arguments against a creative commons approach, the obstacle to an expansion of use is the concern as to the financial impact. Opponents of a creative commons have led the debate by advocating that such an approach will result in a loss of income. This is clearly a genuine concern (although perhaps more so for the music industry) that does need to be addressed. There must be commercial sustainability for a content producer who operates without any content control, and before they begin production they will need to believe sufficient revenue can be generated. Research by Roger Clarke ${ }^{59}$ suggests this is possible. In the first instance, there is the typical scenario of a consumer/viewer paying for a piece of content, either per content piece or general subscription. ${ }^{60}$ By allowing more widespread distribution of content without controls, a wider market can be generated for that content through increased awareness and interest. ${ }^{61}$ This can then be capitalised on by providing direct access to other content that the producer has created through a payment system. ${ }^{62}$ In this respect YouTube has been praised by the BBC as having content that, while being illegal, is "good promotional content for us."63 Content producers also benefit from this model of deferred reciprocity in another way. This is where, although initially their work may be copied or used in some way, they can reciprocate this action. When producing new content a producer can use the work of others as inspiration or as a starting point, helping to reduce the production costs. This course of action, or 'wikinomics', as it has been termed, is in fact gaining growing commercial acceptance as a method of adding economic value to a business. ${ }^{64}$ 
In addition to using widespread uncontrolled content for the purpose of driving subscription services, it can also be used to attract higher advertising premiums. Allowing content to be more accessible, as noted, means that more people have the ability to watch that content. If the product is good, more will want to watch that content as with any traditional television broadcast today. Wider content viewing figures which the Internet brings can result in wider reach for advertisers, leading in turn to higher revenues from content owners. Such an approach to monetising content has in fact been advocated by Jay Adelson, the Chief Executive of Digg. ${ }^{65}$ However, for this benefit to be realised the content must be of sufficient value to the viewer. This is in fact the strategy being adopted by Channel 4, and has already been successfully adopted by Hulu, the joint project between NBC and News Corporation. While the content in question may not have a commons licence it can be argued that it does lend support to the argument that a more expansive commons regime can be commercially viable. ${ }^{66}$

Additionally, another significant benefit for content producers today comes from the fact that technology can be utilised alongside on-demand services to create a profile of the viewer. ${ }^{67}$ This means that advertising can be targeted at people who will be more receptive to those advertisements. This is something of a holy grail for the marketing industry, particularly with the lower production costs that already exist for Internet advertising. Therefore, content producers can charge a significant premium for the advertisements running on that content. The real benefit of this is that the content does not in fact need to be of mass appeal, as the advertiser is getting an interested audience the likelihood of sales flowing from that particular group of viewers is increased.

Therefore, a commons approach would result in a twofold benefit for content producers. They can obtain access to a wider range of material to use within their content productions or as a platform that their new work builds from. If permission is already granted within the attached licence, production can start straight away and legal advice need not be sought, reducing production costs. Additionally, a relaxation of 
copyright controls can actually indirectly generate higher viewing figures or revenue by creating wider exposure from easier distribution amongst friends. People may watch a recommended production on-line for free; if they enjoy it they are then likely to 'tune in' to the next episode and/or buy the box set of the series the latter being something they would not do if they have not previously seen the show for themselves. These commercial benefits are in addition to the benefits to wider society that are gained by increased innovation and the greater access to those creations.

\section{Conclusion}

The proposed AVMS Directive has already been criticised in some quarters over its substantive provisions, in particular, the decision to distinguish between the forms in which audiovisual media content is transmitted. However, the failure of the AVMS Directive to deal with the issue of copyright in the new audiovisual age is arguably the more pressing concern. By not addressing the issue, but then distinguishing between "television broadcasts" and "on-demand services", a loophole has surely been created within the existing copyright protection regime. If the traditional economic justifications for the current copyright protection regime remain valid, then the AVMS Directive is set to fail in its objective to have an innovative audiovisual media sector. However, it is argued that the copyright framework, as well as the audiovisual media sector, would benefit from a wide scale adoption of a creative commons approach to copyright protection. This could not only solve the aforementioned loophole, but also produce more creativity than the current regime due to the wider flexibility and access that such an approach would provide. Whether this scenario will occur remains to be seen, but is unlikely while the creative industry players remain so unconvinced by the revenue potential.

\footnotetext{
${ }^{1}$ By Neal Geach, Lecturer in Law, University of Hertfordshire, N.Geach@ herts.ac.uk

${ }^{2}$ Fifth Report of the Session 2006-07 by the House of Commons Culture, Media and Sport Select Committee, New Media and the Creative Industries, volume 1 at $\mathrm{p} 8$ available at http://www.publications.parliament.uk/pa/cm200607/cmselect/cmcumeds/509/509i.pdf

${ }^{3}$ Government Response to the Culture, Media and Sport Select Committee Report into New Media and the Creative Industries at $\mathrm{p} 1$ available at http://www.culture.gov.uk/NR/rdonlyres/3E8E36E8-3B56-4219-89B2-0623C0AA8AF3/0/375268_GovResponse.pdf

${ }^{4}$ Ibid
} 
${ }^{5}$ Op cit, note 2. The lower figure is that suggested by research by Frontier Economics for the Department of Culture, Media and Sport, the higher figure is put forward by Ofcom. The government puts the figure at 1.8 million.

${ }^{6}$ Op cit, note 3

${ }^{7}$ D. Bainbridge, Introduction to Information Technology Law $6^{\text {th }}$ edition, (Harlow, UK: Pearson Education 2007) at $\mathrm{p} 9$

${ }^{8}$ Giving evidence to the Culture, Media and Sport Select Committee available in volume 2 of their report 'New Media and the Creative Industries' available at http://www.publications.parliament.uk/pa/cm200607/cmselect/cmcumeds/509/6101711.htm

${ }^{9}$ For example, whereas before their consumers may have just been traditional linear broadcasters, today they could also be telecommunications companies.

${ }^{10}$ I.e. those that do not produce their own original content but buy the rights from the producers to broadcast within a define territory.

${ }^{11}$ Op cit, note 2. Sky have driven subscriptions by purchasing the rights to the show ' 24 'they then gain the secondary benefit of potentially higher advertising revenues by having the exclusive right to transmit a popular show.

${ }^{12}$ Graham Lovelace quoted by Martin Croft 'Will legislation kill off mobile TV before it gains an audience? Marketing Week, 5 January, 2006.

${ }^{13}$ The English Premier League Overseas rights were sold for $£ 625 \mathrm{~m}$ see BBC News Press Release 'Premiership in new £625m TV deal' BBC News 18 January 2007 available at http://news.bbc.co.uk/1/hi/business/6273617.stm (accessed 2 February 2008)

${ }^{14}$ This is not confined to the UK; the enhancement of these services is a central tenet of the EU's i2010 Initiative. Recital 4 also states that "audiovisual media services offer significant employment opportunities....and stimulate economic growth and jobs".

${ }^{15}$ In the sense that all the regulations on one area can be found within the same document and thus making it easier for service providers and viewers to know the rights and obligations of each other. The EU is committed to such an approach.

${ }^{16}$ Op cit, note 2

${ }^{17}$ Op cit, note 2 at $\mathrm{p} 81$

${ }^{18}$ Art.3j

${ }^{19} \operatorname{Art} .3 \mathrm{j}(5)$

${ }^{20}$ Recital 27a states the access to events for the purpose of short news reports is without prejudice to Directive 2001/29/EC

${ }^{21}$ 2001/29/EC on the harmonisation of certain aspects of copyright and related rights in the information society

${ }^{22}$ Recital 4

${ }^{23}$ Recital 12

${ }^{24}$ Art.2(e)

${ }^{25}$ Art.3(1)(2)

${ }^{26}$ Art.3(1)

${ }^{27}$ Art 4 also provides for a right of distribution.

${ }^{28}$ Instead, we have the concept of a media service provider which is defined as 'the natural or legal person who has editorial responsibility for the choice of the audiovisual content of the audiovisual media service and determine the manner in which it is organised' - Art.1(b). A 'broadcaster' is defined in art.1(d) as media service provider of television broadcasts.

${ }^{29}$ In art. 1

${ }^{30}$ This right is provided to author of works under art.2(a) of the Copyright Directive.

${ }^{31}$ Naturally the ability to forward on content, even that paid for, to friends is prohibited.

${ }^{32}$ For an overview see Bobbie Johnson, 'Test driving the iplayer' Guardian Unlimited available at http://blogs.guardian.co.uk/technolgy/arcieves/2007/07/27/test_driving the iplayer.html (accessed 28 July 2007)

${ }_{33}^{3}$ Apple's iTunes store does not permit downloads to non-Apple mp3 players.

${ }^{34}$ Jonathan Richards 'Interview: Jay Adelson, chief executive of Digg' Times Online available at http://technology.timesonline.co.uk/tol/news/tech and_web/article3075146.ece (accessed 20 April 2008). In the interview, Adelson highlights how in relation to music, media executives are moving away from DRM and monetising content in other ways. As a replacement he suggests embedding files with technologies that monitor how many times it is downloaded or streamed and then using this information to set advertising rates.

${ }^{35}$ This is replicated in the USA with the Digital Millennium Copyright Act

${ }^{36}$ s.296ZB Copyright, Design and Patents Act 1988, although the "Gowers Review of Intellectual Property" suggests digital copyright offences should all carry the same 10 year penalty as physical infringement.

${ }^{37}$ In that they are simply trying to watch something that they have paid for.

${ }^{38}$ If they have in fact even read these terms and conditions

${ }^{39}$ Interestingly, the Copyright Directive suggests in Recital 38, 39 and 44 that Member States should be able to allow private use reproduction, particularly analogue copies. It is more concerned about digital reproduction due to the economic impact on producers but in this digital audiovisual age this distinction would no longer seem valid. In the UK, the 'Gowers Review of 
Intellectual Property' has called for reform in this area to allow for a private copying so that format shifting can take place. A consultation period on the proposals closed on April 8, 2008.

${ }^{40}$ In a telephone interview with Lawrence Lessig, recorded in the latter's book, The Future of Ideas (New York: Vintage Books, 2001)

${ }^{41}$ For example Woods v Universal City Studios Inc., 920 F. Supp. 62 (SDNY 1996) concerning the film 12 Monkeys

${ }^{42}$ Anupam Chander and Madhavi Sunder, 'The Romance of the Public Domain', California Law Review, Vol. 92 (2004)

${ }^{43}$ Ibid at p1341

${ }^{44}$ Garrett Hardin, 'The Tragedy of the Commons', Science 162 (1968)

${ }^{45}$ Giving evidence to the Department of Culture, Media and Sport Select Committee documented in 'New Media and the Creative Industries', Op cit, note 2 at p23

${ }^{46} \mathrm{Be}$ it by the private sector and the market, or by the state.

${ }^{47}$ In the sense that it can be used without permission or where permission is needed it is granted neutrally. The latter meaning without regard to the user, there is no discrimination in allowing access.

${ }^{48}$ All communication systems have been described as having three layers by Yochai Benkler. The physical meaning the hardware that runs the system; the code layer, meaning what runs the hardware and the content layer, what is actually transmitted. Yochai Benkler, 'From Consumers to Users: Shifting the Deeper Structures of Regulation' Federal Communications Law Journal 52 (2000) 561

${ }^{49}$ Laurence Lessig The Future of Ideas (New York: Vintage Books, 2001) at p25

${ }^{50}$ Whereby the intelligence of the system is pushed to the ends i.e. the user's computer or application leaving the network free to simply transmit data. As such it is not intelligent enough to discriminate between different application and content.

${ }^{51}$ Content can be added without the consent of anyone, while the code layer is neutral in not discriminating between different forms of content.

${ }^{52}$ Such as Director General Mark Thompson at the BBC

${ }^{53}$ This is the charge labeled against YouTube by Viacom who are seeking \$1bn in damages. See Anne Broache and Greg Sandoval "Viacom sues Google over YouTube clips" CNet News 13 March 2007 available at http://news.com.com/Viacom+sues+Google+over+YouTube+clips/2100-1030_3-6166668.html (accessed 13 March 2008)

${ }_{55}^{54}$ Op cit, note 49 at p249

${ }^{55}$ Judge Alex Kozinski dissenting in the US case of Vanna White v Samsung Elecs. Am., Inc.; David Deutsch Assocs.; 989 F. 2 d 1512,1514 (1993) 27

${ }^{56}$ For more detail as to the different licences and the operation of the creative commons see http://creativecommons.org (accessed 8 April 2008)

${ }^{57}$ This threat of litigation nearly ensured that, what in the author's view is one of the most creative musical works for some time, 'The Grey Album' by the producer Danger Mouse never reached the public audience that it has. The album consists of the music of The Beatles' 'White Album' mixed with the lyrics of 'The Black Album' by Jay-Z.

${ }_{58}^{58}$ Op cit, note 2 at $\mathrm{p} 23$

${ }^{59}$ Roger Clarke, 'Business Models to Support Content Commons', SCRIPT-ed Vol.4, Issue 1 March (2007)

${ }^{60}$ The options pursued currently in the market

${ }^{61}$ For example, amongst friends or even by free download; such a person may discover new content by a producer which they like so much they go and purchase the related content.

${ }_{62}$ An example until recently would have been said to have been nytimes.com.

${ }^{63}$ Ashley Highfield BBC Director of Future Media and Technology quoted by Tim Weber 'BBC strikes Google-YouTube deal', BBC News 2 March 2007 available at http://news.bbc.co.uk/go/pr/fr/-/1/hi/business/6411017.stm (accessed 3 March 2008)

${ }^{64}$ See for example Don Tapscott and Anthony D. Williams WIKINOMICS: How Mass Collaboration Changes Everything (London: Atlantic Books 2007)

${ }^{65}$ Op cit, note 34

${ }^{66}$ Informitv News Release 'Hulu dawn exploits early rise in online video viewing', Informitv.com 17 April 2008 available at http://informitv.com/articles/2008/04/17/huludawnexploits/ (accessed 21 April 2008)

${ }^{67}$ Especially with a subscription service although; clearly there are some data protection issues here but these are outside the scope of present discussion. 